\title{
Saving lives with lung cancer screening
}

\author{
Wolfgang Hilbe $\cdot$ Andreas Pircher
}

Lung cancer is the number one reason for cancer-related death in Austria and many other countries, especially due the fact that the majority of patients are diagnosed at an advanced stage of the disease. Two large trials (NLST and NELSON) proved the efficacy of low-dose CT (LD-CT) for lung cancer screening [1, 2]. Lung cancer deaths were decreased and early diagnosis facilitated curative treatment options. Thus, the risk to die from lung cancer was reduced by $26 \%$ in the NELSON trial.

These two large trials applied age and smoking history to define the screening population. However, adding additional factors resulting in a multivariable lung cancer risk prediction model, as discussed by Asshoff et al. [4], showed a significant better performance than the criteria used in the NLST.

The perspective of the radiologist is discussed by G. Widmann [5]. Criteria of a board certification and expertise in lung nodule reporting systems including volume measurement are essential to reduce falsepositive results. Furthermore the implementation of a national accreditation program is recommended to guarantee nationwide equal standards and quality of screening. He pointed out the necessity of a low effective radiation dose of $<1.6 \mathrm{mSv}$, which is lower than the natural background radiation. This must be balanced with having to deal with $4 \%$ major complications from cytology and needle biopsy asking for a critical ap-

Prim. Univ.-Prof. Dr. W. Hilbe $(\bowtie)$

Department of Oncology, Hematology and Palliative Care, Wilhelminenspital, Montleartstraße 37, 1160 Vienna, Austria wolfgang.hilbe@wienkav.at

\section{PD Dr. med. univ. A. Pircher}

Department of Hematology and Oncology, Internal

Medicine V, Medical University of Innsbruck,

Anichstraße 35, 6020 Innsbruck, Austria

Andreas.Pircher@i-med.ac.at praisal of each invasive intervention decided and discussed in a multidisciplinary nodule evaluation board.

Screening will make surgical resections three times as likely as compared to the control arm. The impact for the surgeon's daily practice is summarized by $\mathrm{F}$. Augustin and $\mathrm{H}$. Maier [6]. They critically highlighted aspects of sufficient surgical resources and technical challenges including limited resections of very small nodules.

From the oncologist's perspective Kocher et al. [7] pointed out that an increasing number of early stage patients could have an impact on the study landscape asking for more evidence of adjuvant or neoadjuvant interventions. The risk of overdiagnosis especially in elderly patients and those with comorbidities has to be critically observed.

Considering the high smoking prevalence in Central Europe the present initiative to implement lung cancer screening activities seem to be contradictory. Therefore, major strategies and public awareness should be focused on smoking prevention strategies. Neuberger [3] presents in his review the strategies of different countries for a successful tobacco control. Major issues for a successful policy are prices of tobacco and smoke-free legislation. A $10 \%$ increase in the real price of cigarettes decreases cigarette consumption by 5-7\%! Additionally, comprehensive bans of tobacco advertising, promotion and sponsoring are necessary.

Offering LD-CT screening to a "healthy smoking population" will challenge our health care systems and new questions need to be answered. How could we integrate efficient smoking cessation programs, how could we manage the additional radiological services required, how should we deal with accidental findings on LD-CT scans, how to prevent false positive results? The central role of an interdisciplinary board for the discussion of the subsequent invasive 
procedure is recommended by all experts, but how to provide a time efficient algorithm for these consulting services remains to be answered. Nevertheless, the authors all agreed that "it is time to screen" in daily practice.

Conflict of interest W. Hilbe and A. Pircher declare that they have no competing interests.

\section{References}

1. National Lung Screening Trial Research Team, Aberle DR, Adams AM, Berg CD, Black WC, Clapp JD, Fagerstrom RM, Gareen IF, Gatsonis C, Marcus PM, Sicks JD. Reduced lungcancer mortality with low-dose computed tomographic screening. NEnglJ Med. 2011;365(5):395-409.

2. De Koning H, Van Der Aalst C, Ten Haaf K, Oudkerk M. PL02.05 effects of volume CT lung cancer screening: mortality results of the NELSON randomised-controlled population based trial. JThorac Oncol. 2018;13(10):185.

3. Neuberger M. Tobacco control: prevention and cessation in Europe. Memo. 2019;12. https://doi.org/10.1007/s12254019-0485-6.
4. Asshoff M, Weiss G, Tancevski I. Whom to screen? A view on lung cancer screening from the pneumologist's perspective. Memo. 2019;12. https://doi.org/10.1007/s12254-0190501-x.

5. Widmann G. Challenges in implementation of lung cancer screening-radiology requirements. Memo. 2019;12. https://doi.org/10.1007/s12254-019-0490-9.

6. KocherF, PallG.Lung cancer screeningfrom theoncologist's perspective. Memo. 2019;12. https://doi.org/10.1007/ s12254-019-0492-7.

7. Ng C, Maier H, Augustin F. Lung cancer screening-the surgeon's perspective. Memo. 2019;12. https://doi.org/10. 1007/s12254-019-0502-9.

Publisher's Note Springer Nature remains neutral with regard to jurisdictional claims in published maps and institutional affiliations.

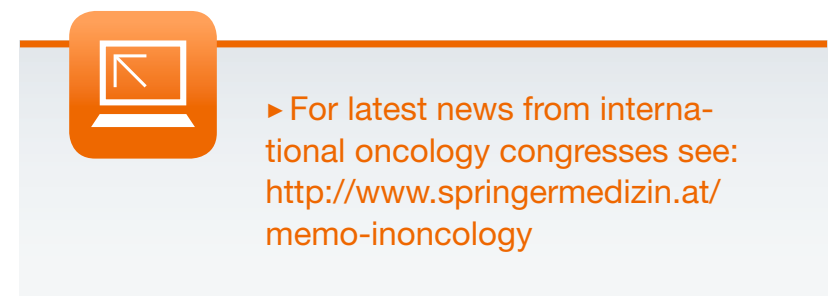

